\title{
Giemsa Banding Pattern of a Heritable 1q+ Variant Chromosome: A Possible Partial Duplication
}

\author{
JOHN R. LOBITZ, BARBARA K. MCCAW, and FREDERICK HECHT \\ From the Division of Medical Genetics and Departments of Pediatrics and Medicine, Child Development and \\ Rehabilitation Center, University of Oregon Medical School, Portland, Oregon 97201, USA
}

One morphological variant of chromosome 1 in man differs from the more usual form of this chromosome in being longer and more submetacentric. This is due to increased length of the long arm and because there is apposition of chromatids in the paracentromeric region of the long arm (q). This variant, or similar appearing variants of chromosome 1 , have been found in 1 per 100 to 1 per 1000 newborns in the United States (Lubs and Ruddle, 1971).

Previous studies have reported $1 \mathrm{q}+$ variants in individuals with a variety of anomalies as well as in phenotypically normal individuals (Cooper and Hernits, 1963; Donahue et al, 1968). Since the same anomaly has never been associated with the variant chromosome in more than one instance, and since phenotypically normal individuals have also been reported carrying the variant chromosome, it can be concluded that it is a normal variant which causes no obvious phenotypic abnormality.

Family studies of $1 \mathrm{q}+$ variants have, together with gene linkage studies, served to assign a series of genes to chromosome 1. These include the loci for the Duffy blood group (Donahue et al, 1968; Ying and Ives, 1968), congenital pulverulant cataract (Renwick and Lawler, 1963/1964), and amylase 2 (Karamýt, Adámek, and Vrba, 1971; Hill, Rowe, and Lovrien, 1972).

We investigated a 3-generation Caucasian family with a variant chromosome 1 (Fig. 1). The proposita was originally ascertained because of mild mental retardation but had no physical anomalies. Other members of the family were phenotypically normal. We designed studies (1) to determine the effect of the hypotonic treatment upon the appearance of the variant; and (2) to learn if the apparent increase in length was due to uncoiling or to the addition of chromosomal material to $1 \mathrm{q}$.

\section{Nomenclature}

Various terms have been applied to variants of chromosome 1 that have an increased length of the

\footnotetext{
Received 10 February 1972.
}

long arm. Terms such as 'increased secondary constriction region' (Lubs and Ruddle, 1971) indicate that the resultant increase in length occurs in a particular segment of 1q. Other terms such as 'uncoiler' imply a specific mechanism for the increase in length (Donahue et al, 1968). We have chosen to use the designation ' $1 \mathrm{q}+$ variant' or more simply ' $1 \mathrm{q}+$ ' to avoid such connotations.

\section{Materials and Methods}

Peripheral blood was obtained from each family member. Lymphocytes were cultured and harvested after $72 \mathrm{hr}$ (Moorhead et al, 1960). The fixative was methanol: acetic acid (3:1) and slides were made by flame-drying.

To test the effect of differing hypotonic treatments, the following 3 regimens were tried on different aliquots of the cell suspension: $\mathrm{a}-0.075 \mathrm{M} \mathrm{KCl}$ for $10 \mathrm{~min}$ at room temperature; $b-0.93 \%$ sodium citrate for $10 \mathrm{~min}$ at room temperature; and c-distilled water for $30 \mathrm{~min}$ at $37^{\circ} \mathrm{C}$.

Metaphases from each family member were scored visually for the presence of the $1 \mathrm{q}+$ variant. Criteria for determining that a metaphase manifested the $1 \mathrm{q}+$ variant chromosome were that: (1) it contained a long, submetacentric chromosome 1 due to elongation of $1 \mathrm{q}$; and (2) the suspected variant chromosome showed close apposition of chromatids in the paracentromeric region of the long arm.

The acetic/saline/Giemsa (ASG) procedure was employed to reveal chromosome banding (Sumner, Evans, and Buckland, 1971). Lymphocytes were prepared by regimen a and fixed in methanol:acetic acid $(3: 1)$ for 15 minutes. Slides were made by flame drying, then incubated in $2 \times \operatorname{SSC}(0.3 \mathrm{M} \mathrm{NaCl}$ and $0.03 \mathrm{M}$ trisodium citrate) at $60^{\circ}$ for $1 \mathrm{hr}$, rinsed once in distilled water, and stained with a Giemsa solution (Harleco brand, $1 \mathrm{ml}$ in $100 \mathrm{ml}, \mathrm{pH} 6.5$ phosphate buffer, for $12 \mathrm{~min}$ or with Gurr's Giemsa 'R66', $1 \mathrm{ml}$ in $50 \mathrm{ml}, p \mathrm{H} 6.8$ phosphate buffer, for 90 minutes).

\section{Results}

Family Study. Of the 9 family members, 4 were found to be heterozygous for the $1 \mathrm{q}+$ variant (Figs. 1 and 2). Karyotypes from the 9 
individuals otherwise appeared unremarkable, providing no hint as to the presence of a subtle reciprocal or insertional translocation. Caliper measurements were also normal in all the karyotypes from the 9 family members, except in the case of the $1 \mathrm{q}+$ variant present in the $\mathbf{4}$ heterozygotes.

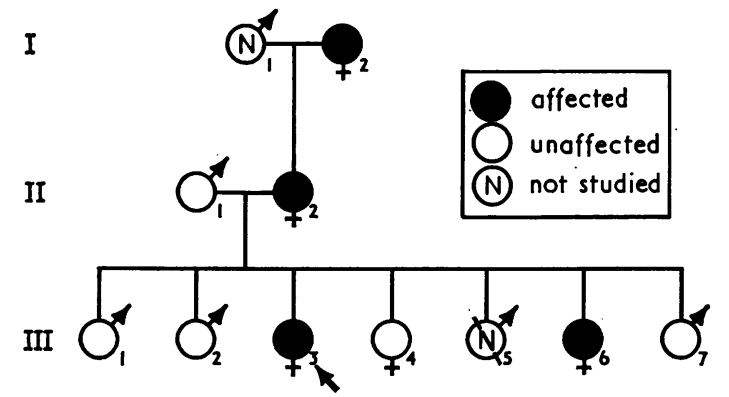

Fig. 1. Pedigree of the family in which the variant chromosome 1 segregates.
Effect of Hypotonic Treatment. A representative metaphase spread is illustrated in Fig. 2. Treatment $\mathrm{c}$ (distilled water for 30 minutes) resulted in an increased proportion of cells with an incomplete complement of chromosomes, probably due to increased breakage of the cell membrane. The variation in length and the increased submetacentricity of the $1 q+$ variant were apparent in essentially all metaphases from each of the 4 heterozygotes, independent of the hypotonic treatment.

Apposition of chromatids was influenced by the type of hypotonic treatment. Between 50 and 100 metaphases from each regimen were scored for this criterion. Apposition in the paracentromeric region of $1 \mathrm{q}$ was observed in $25-35 \%$ of $1 \mathrm{q}+$ metaphases after $\mathrm{KCl}$ treatment (regimen a), $35-45 \%$ after sodium citrate (regimen b), and in $50-60 \%$ of cells after aqueous hypotonic treatment (regimen c).

The overall chromosome morphology was best and the ASG-banding patterns most distinct after

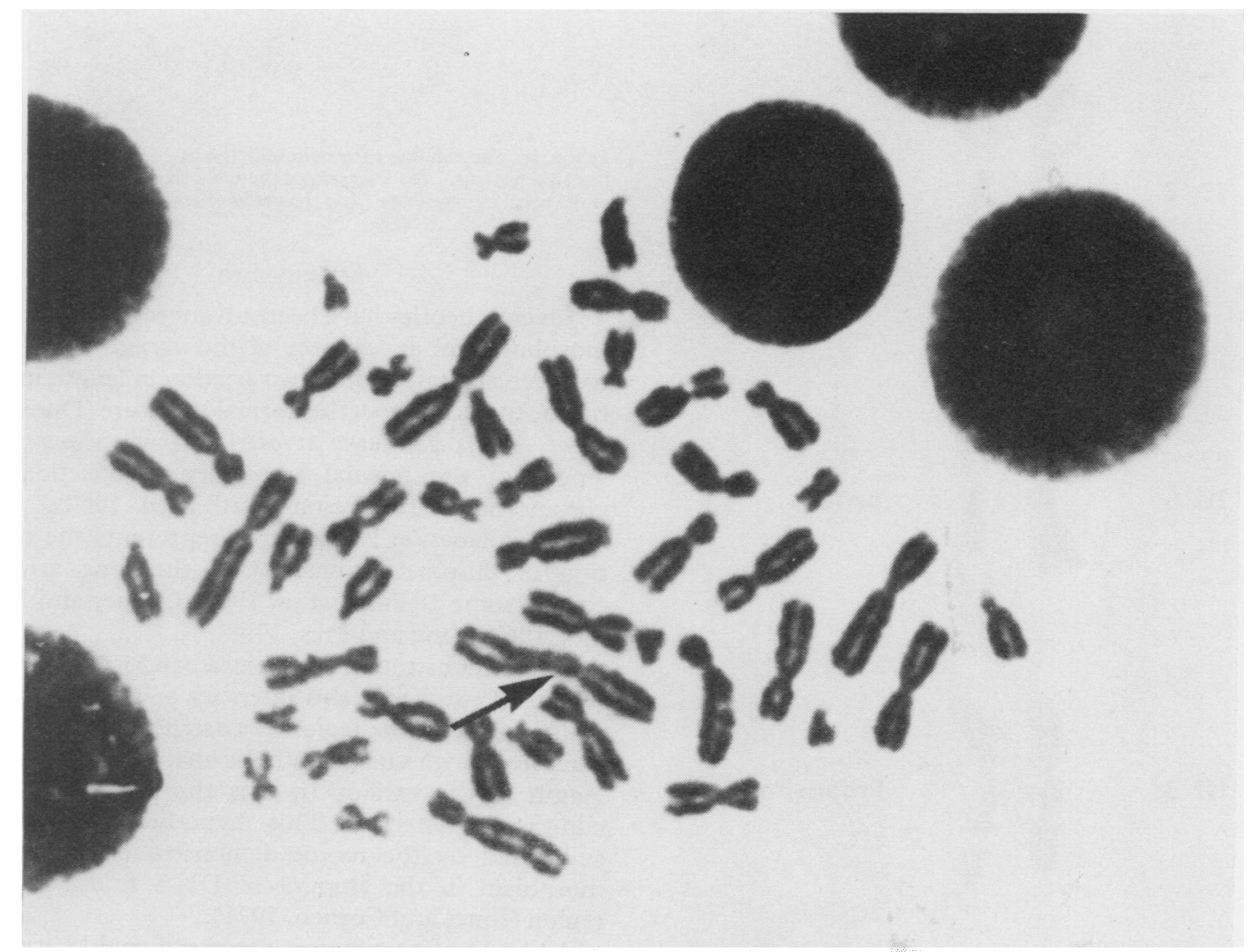

FIG. 2. A representative metaphase from an individual who carries the variant chromosome 1 (arrow) stained with Giemsa without the pretreatment to produce differential banding. 
$\mathrm{KCl}$ hypotonic treatment (regimen a). This regimen was therefore used to prepare chromosomes for ASG-banding studies.

ASG-Banding Studies. The ASG patterns of the usual chromosome 1 and the $1 \mathrm{q}+$ variant chromosome were compared. The banding patterns distal to the prominent secondary constriction on 1q appeared identical. However, differences were observed in the region between the centromere and the secondary constriction. In that region the usual chromosome 1 had a single dark band, whereas the $1 \mathrm{q}+$ chromosome consistently had 2 dark

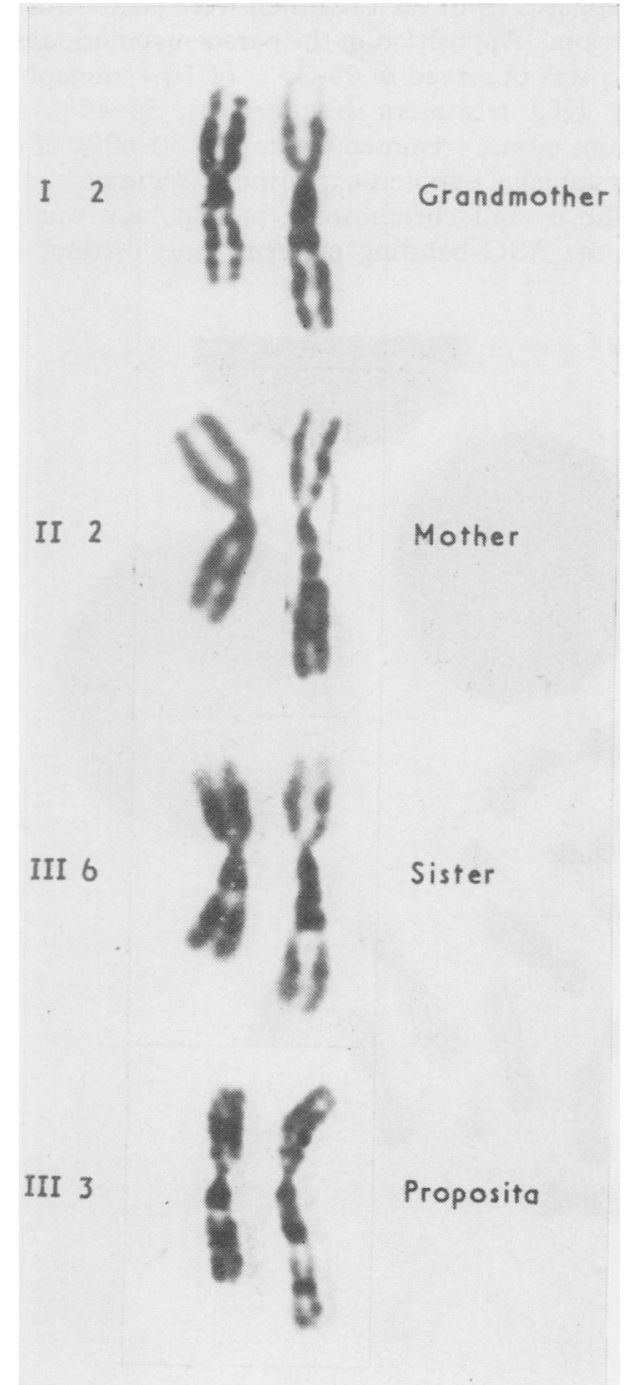

Fig. 3. A composite of the chromosome 1 pairs from the 4 individuals heterozygous for the $1 \mathrm{q}+$ variant. bands with an intervening lightly stained band (Fig. 3). The 2 dark bands on $1 \mathrm{q}+$ were similar in size and stained with the same intensity as the single dark band in this region on the usual chromosome 1 (Fig. 4a). In some cells when 2 bands could be resolved in the region between the centromere and the secondary constriction on the long arm of the usual chromosome No. 1 , the same region of the $1 \mathrm{q}+$ variant showed a corresponding increase in the number of subunits.

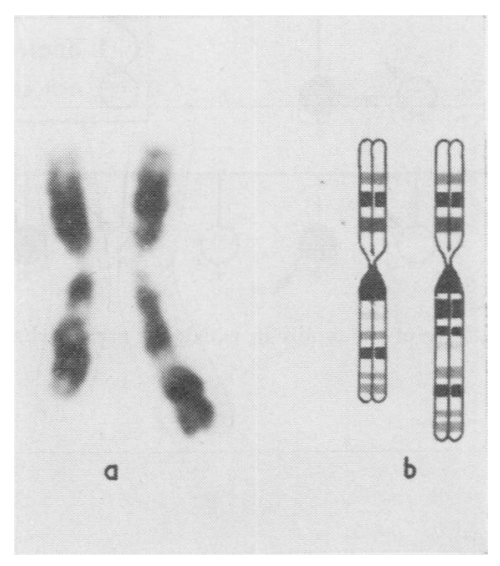

FIG. 4. (a) The banding pattern in both the usual chromosome 1 and the $1 \mathrm{q}+$ variant. (b) Diagram of the most frequently seen pattern of the usual chromosome 1 and the variant homologue.

\section{Discussion}

Several theories have been advanced to explain the morphological appearance of the variant $1 \mathrm{q}+$. It has been suggested that the variation in length might be due to uncoiling of the normal structure (Donahue et al, 1968; Kamarýt et al, 1971) or to increased length of the normal secondary constriction on chromosome 1 (Ferguson-Smith et al, 1962). Another explanation is that $1 \mathrm{q}+$ represents the addition of chromatin material to the long arm of chromosome 1 (Patau et al, 1961; Cooper and Hernits, 1963; Ying and Ives, 1968).

Our demonstration of an extra band in the variant region of equal size and intensity as the band normally found in this region of chromosome 1 is most consistent with the hypothesis that the increase in length in the variant $1 \mathrm{q}+$ is the consequence of additional material. This hypothesis is further supported by the recent demonstration of a polymorphism in the amount of DNA found in this region (Jones and Corneo, 1971).

Addition of chromosome material could occur by one of 2 mechanisms, either translocation or partial duplication. A translocation could be of 2 types, 
insertional or reciprocal. A reciprocal translocation would presumably result in a different banding pattern on $1 \mathrm{q}+$ distal to the break point, which was not observed. We have shown that the extra material occurs in an internal segment of the long arm of the chromosome 1 between the centromere and the often prominent secondary constriction. An insertional translocation is not likely because it would require a minimum of 3 simultaneous chromosome breaks.

The most probable source of extra chromatin material in the variant chromosome 1 is partial duplication (Cooper and Hernits, 1963; Ying and Ives, 1968). One mechanism by which this could have occurred is unequal crossing-over in meiosis. There is evidence for the occurrence of this process on the gene level in humans, for example, in the haemoglobin system (Nance, 1963) and with haptoglobin (Smithies, Connell, and Dixon, 1962). Further evidence for this mechanism would be provided by the observation of the presumed reciprocal product, consisting of a chromosome 1 with an abbreviated long arm and the loss of the normal single dark band.

Although unequal crossing-over should occur randomly, the existence of the partially duplicated product without any accompanying phenotypic abnormalities would be more likely to occur in an area of reiterated DNA sequences. In this connection, it is interesting that with a technique for visualizing centromeric-associated heterochromatin (Arrighi and Hsu, 1971) the variant region on chromosome 1 stains heavily and hence has been postulated to contain highly redundant DNA sequences (Craig-Holmes and Shaw, 1971; Lubs and Ruddle, 1971). Moreover, RNA complementary to satellite II DNA has been found to anneal most prominently to the paracentromeric region of chromosome 1 , suggesting that this region is particularly rich in reiterated sequences (Jones and Corneo, 1971). Variation in this region would therefore be consistent with the absence of phenotypic abnormalities in the families in which the variant $1 \mathrm{q}+$ segregates.

Caution should be taken not to extend the results reported here without appropriate studies to other $1 \mathrm{q}+$ variants segregating in unrelated families.

\section{Summary}

A $1 \mathrm{q}+$ chromosome variant was found to segregate through 3 generations of a family. The $1 \mathrm{q}+$ variant showed, aside from increased length of the long arm (q), close apposition of chromatids in the paracentromeric region of $\mathrm{q}$. The frequency with which chromatid apposition was observed depended upon the type of hypotonic treatment. Acetic/ saline/Giemsa banding studies revealed extra bands in the paracentromeric region of $1 \mathrm{q}$, consistent $w$ ith the addition of chromosome material. These findings are most easily explained by partial chromosome duplication due to uneven crossing-over.

We thank Herman Wyandt for advice on stains, Norman McKay for photographic assistance, Sue Underwood for family work, and Patricia Evans for editorial assistance. Mr Lobitz was supported by a fellowship from the Oregon Heart Association. The investigation was supported by grants from the Children's Bureau (for a genetics programme) and National Institute of Health (AM CA 13173 and HD 05082).

\section{REFERENCES}

Arrighi, F. E. and Hsu, T. C. (1971). Localization of heterochromatin in human chromosomes. Cytogenetics, 10, 81-86.

Cooper, H. L. and Hernits, R. (1963). A familial chromosome variant in a subject with anomalous sex differentiation. American fournal of Human Genetics, 15, 465-475.

Craig-Holmes, A. P. and Shaw, M. W. (1971). Polymorphism of human constitutive heterochromatin. Science, 174, 702-703.

Donahue, R. P., Bias, W. B., Renwick, J. H., and McKusick, V. A. (1968). Probable assignment of the Duffy blood group locus to chromosome 1 in man. Proceedings of the National Academy of Sciences of the United States of America, 61, 949-955.

Ferguson-Smith, M. A., Ferguson-Smith, M. E., Ellis, P. M., and Dickson, M. (1962). The sites and relative frequencies of secondary constrictions in human somatic chromosomes. Cytogenetics, 1, 325-343.

Hill, C., Rowe, S., and Lovrien, E. (1972). Probable linkage between human serum amylase $\left(\mathrm{Amy}_{2}\right)$ and Duffy blood group. Nature, 235, 162-163.

Jones, K. W. and Corneo, G. (1971). Location of satellite and homogeneous DNA sequences on human chromosomes. Nature New Biology, 233, 268-271.

Kamarýt, J., Adámek, R., and Vrba, M. (1971). Possible linkage between uncoiler chromosome Un 1 and amylase polymorphism Amy 2 loci. Humangenetik, 11, 213-220.

Lubs, H. A. and Ruddle, F. H. (1971). Chromosome polymorphism in American negro and white populations. Nature, 233, 134-136.

Moorhead, P. S., Nowell, P. C., Mellman, W. J., Batipps, D. M., and Hungerford, D. A. (1960). Chromosome preparations of leukocytes cultured from human peripheral blood. Experimental Cell Research, 20, 613-616.

Nance, W. E. (1963). Genetic control of hemoglobin synthesis. Science, 141, 123-130.

Patau, K., Therman, E., Inhorn, S. L., Smith, O. W., and Ruess, A. L. (1961). Partial trisomy syndromes. II. An insertion as cause of the OFD syndrome in mother and daughter. Chromosoma, 12, 573-584.

Renwick, J. H. and Lawler, S. D. (1963/1964). Probable linkage between a congenital cataract locus and the Duffy blood group locus. Annals of Human Genetics, 27, 67-84.

Smithies, O., Connell, G. E., and Dixon, G. H. (1962). Chromosomal rearrangements and the evolution of haptoglobin genes. Nature, 196, 232-236.

Sumner, A. T., Evans, H. J., and Buckland, R. A. (1971). New technique for distinguishing between human chromosomes. Nature New Biology, 232, 31-32.

Ying, K. L. and Ives, E. J. (1968). Asymmetry of chromosome number 1 pair in three generations of a phenotypically normal family. Canadian fournal of Genetics and Cytology, 10, 575-589. 